\title{
Chemical Analysis (GC-FID-MS) and Antimicrobial Activity of Parmotrema perlatum essential oil Against Clinical Specimens
}

\author{
MUAZZAM SHERIFF MAQBUL'ㄹ, HUSAM MOHSEN BIN ALHASEL², DUAA HABIB MAJID², \\ TASNEEM NAWAL MOMEN ${ }^{2}$, HANAN AHMED MOHAMMED ALHAZMI', FAISAL \\ MOHAMMED SAUD AL JEDDANI², RIYADH TAWFEEQ WASSAL AL MALKI², \\ AEJAZ A. KHAN ${ }^{3}$ and S. M. SHAKEEL IQUBAL ${ }^{3 *}$
}

${ }^{1}$ Department of Microbiology and Immunology, Ibn Sina National College for Medical Studies, Jeddah, Kingdom of Saudi Arabia.

${ }^{2}$ Medicine Program, Ibn Sina National College for Medical Studies, Jeddah, Kingdom of Saudi Arabia. ${ }^{3}$ Department of General Science, Ibn Sina National College for Medical Studies, Jeddah, Kingdom of Saudi Arabia.

${ }^{\star}$ Corresponding author E-mail: shakeeliqubal@ gmail.com

http://dx.doi.org/10.13005/ojc/350610

(Received: October 25, 2019; Accepted: November 26, 2019)

\begin{abstract}
ABSRTACT
The major study of this work was to evaluate the chemical composition and the inhibitory components of Parmotrema perlatum against the clinically isolated specimens of Staphylococcus, Streptococcus, Escherichia, Pseudomonas and Candida. The GC-FID-MS by using a Trace GC Ultra apparatus MS DSQ II detectors and FID-MS splitter under the operating conditions of a polar capillary column was employed to determine the chemical composition of Parmotrema perlatum essential oil. Amino acids viz (38.1\%) and cymene (29.1\%) were the most adequate constituents in this oil. The antibacterial activity of Parmotrema perlatum oil was tested against standard strains of bacteria and clinical strains isolated from patients with infections of the oral cavity, abdominal cavity, respiratory, genitourinary tracts, skin, and from the hospital environment. Kirby-Bauer disc diffusion technique was employed to determine the susceptibility of the organism towards the Parmotrema perlatum essential oil exhibited very strong antimicrobial activity to inhibit the growth of the clinical specimens. Application of natural antimicrobial based essential oil from Parmotrema perlatum can be potential source in the treatment and prevention of different types of infections as an alternative to the chemical - based antibiotics based on the investigation.
\end{abstract}

Keywords: Chemical analysis, Antimicrobial activity, Parmotrema perlatum oil, Essential oil, Clinical specimens.

INTRODUCTION

Parmotrema perlatum is commonly known as black stone flower or kalpasi, is a species of lichen used as a spice in India1. This spice has the potential to be an effective antimicrobial therapy for

This is an Open Access article licensed under a Creative Commons license: Attribution 4.0 International (CC- BY). Published by Oriental Scientific Publishing Company @ 2018 
many pathogens especially against opportunistic Gram-negative bacteria which has become as one of the major challenges for the present environment due to the rise in multi-drug resistant mutant organisms developed as a result of antibiotic abuse..$^{2-3}$ Gram-positive cocci such as Staphylococcus species has recently shown the significant rise in the infection and this essential oil is one of the choices for the safest \& effective medicine that could be to treat bacterial infections ${ }^{4-9}$. The Parmotrema perlatum essential oil also has antifungal activity against the medically important yeast infections caused by Candida species ${ }^{10-11}$. The antibacterial components such as phenolic serves as a good antibacterial agents in the Parmotrema perlatum essential oils proved to be a very important weapon versus multidrug-resistant strains of bacteria and there is no proof of the rise of resistant type of bacteria ${ }^{9,12}$. This has proved once again that nature has blessed with plenty of natural resources available towards almost all types of infections and it will be our needs which will drive closer towards them. Thus, the need of the hour is to perform these types of studies to discover the hidden natural resources to resurrect the ancient effective forgotten techniques to treat several infections as a combat against antibiotic abuse causing the germination of mutant multidrug-resistantt organism. Parmotrema perlatum essential oil chemical analysis was done by GC-FID-MS to find out its chemical ingredients which inhibits infectious organisms by the antimicrobial components present ${ }^{1,9,11,13-14}$.

\section{MATERIALS AND METHODS}

\section{Material and reagents}

Parmotrema perlatum essential oil, Clinical sample from a patients, Standard strain of the bacterium and different types of $\mathrm{Hi}$ Media culture plate were used.

\section{Specimen collection}

The standard strains, Staphylococcus, Streptococcus, Escherichia, Pseudomonas and Candida species were employed against the study of the clinical specimens of Staphylococcus, Streptococcus, Escherichia, Pseudomonas and Candida species which were collected from the various Jeddah, hospitals ${ }^{7-8,15}$.

\section{Identification of bacterial strain}

\section{Isolation and purification of the clinical specimens}

Staphylococcus specimen was identified by using the standard microbiological techniques $9,14,16$ by culturing on blood culture media with $5 \%$ of sheep's erythrocytes and also culturing on mannitol salt agar. The ability of the bacterium to produce catalase and coagulase was determined by slide test. The Gram staining showed Grampositive cocci in clusters.

Streptococci specimen was identified by culturing on Blood culture media with 5 percent of sheep's erythrocyte-forming beta-hemolytic colonies. The inability of the bacterium to give coagulase \& catalase was determined by a slide test. The Gram staining showed Gram-positive cocci in chains.

Escherichia specimen was identified by culturing on Mac Conkey culture media forming pink lactose fermenting colonies and were identified by biochemical methods with motility test by hanging drop method to differentiate from other Gramnegative entero-bacteria and determined by the enzymatic test of oxidase negative todifferentiate from Pseudomonas.

Pseudomonas specimen was identified by culturing on Mac Conkey culture media forming characteristic green pigmented nonlactose fermenting colonies and were identified by biochemical methods with motility test by hanging drop method to differentiate from other Gramnegative entero-bacteria and determined by the enzymatic test of oxidase-positive to differentiate from Escherichia.

Candida specimen was identified by culturing on Sabaraud's dextrose culture media forming pale white oval colonies and determining with a rapid screening germ tube test by inoculating 
in the serum of the sheep and incubating at $37^{\circ} \mathrm{C}$ for $3 \mathrm{~h}$ to check its virulence factor. The Gram staining result shows Gram-positive oval yeast budding cells. The chlamydospore formation testwas done on cornmeal agar incorporated with tryptophan as a confirmatory test.

\section{Parmotrema perlatum essential oil preparation}

100.00 of Parmotrema perlatum grounded using mortar and pestle. The grounded powder dissolved in $400.00 \mathrm{ml}$ distilled water and boiled at $100^{\circ} \mathrm{C}$ for about 1 hour. The solution is filtered using filter paper ${ }^{1}$. Further this oil was analyzed by GC-FID-MS by utilizing a GC.

\section{Antimicrobial susceptibility testing}

The following three methodologies were employed $^{9,14,16}$ to determine the antimicrobial susceptibility testing for the Parmotrema perlatum essential oil against isolated and purified collected clinical isolates along with the standard strains. Different types of sstandard antibiotics were used for the study to compare antimicrobial susceptibility results to correlate with the Parmotrema perlatum essential oil.

\section{Kirby-Bauer method or disc diffusion method}

The disk diffusion method (Kirby-Bauer) is more suitable for routine testing in a clinical lab where a large number of isolates are tested for susceptibility to antimicrobial effects. A standardized antibiotic disc was prepared and incubated at $37^{\circ} \mathrm{C}$ soaked overnight in the Parmotrema perlatum Essential oil and incorporated on Mueller-Hinton culture media. The overnight incubation at $37^{\circ} \mathrm{C}$ shows drug susceptibility of microorganisms This method provides a quick way to determine the efficacy of the antimicrobial properties. The comparative study was performed by incorporating all the standard strains respectively by the same Mueller-Hinton agar plate method by repeating the procedure. The results were observed and recorded.

\section{Minimum inhibitory concentration-Tube dilution method}

Minimum concentration required by Parmotrema perlatum essential oil to inhibit the clinical isolates was determined by this MIC test by using different sets for each clinical specimens inoculated in peptone water along with the antimicrobial agents and after overnight incubation at $37^{\circ} \mathrm{C}$ in an incubator where a serial dilution of the respective Parmotrema perlatum essential oil is prepared and inoculated with the inoculum The MIC values were observed with the last tube with turbidity determining the bacteriostatic effect of the respective essential oils and were recorded.

\section{Minimum bactericidal concentration method}

The minimum bactericidal concentration (MBC) was performed to determine the lowest concentration of all the Parmotrema perlatum essential oils required for the bactericidal effect on the clinical isolates by dividing the appropriate culture plate for each isolate into six portions representing each dilution of MIC. The sample from each dilution was inoculated on the each designated portions for the respective dilutions for all the Parmotrema perlatum essential oil MIC dilutions separately. The inoculated plates were incubated overnight at $37^{\circ} \mathrm{C}$ to evaluate the bactericidal activity of the Parmotrema perlatum essential oils against the respective isolate.

Note: Sabaraud's media was used for the demonstration of the anti-fungal activity of Candida against Parmotrema perlatum essential oil by following the above methodology ${ }^{1,10}$.

\section{RESULTS AND DISCUSSION}

\section{Chemical components analyzed from the tested Parmotrema perlatum essential oil.}

The chemical components analysis of the Essential oil derived from the tested Parmotrema perlatum was found to meet all the requirements to be a good antimicrobial substance. The content of tested Parmotrema perlatum essential oil constitutes Alkaloids Carbohydrates, Phytosterols, Fixed oils, fats, Phenolic compounds, Tannins, Proteins, Amino acids, Gums, mucilage,-Saponin, carvacrolas etc. listed (Table 1). 
Table 1: Analysis of Chemical Components Procured from the tested Parmotrema perlatum essential oil by GC-FID-

\begin{tabular}{lcc}
\hline Compound & Total oil $\%$ & R. indices \\
\hline Alkaloids & 0.60 & 932.00 \\
Carbohydrates & 1.90 & 936.00 \\
Camphene & 1.20 & 950.00 \\
Phytosterols & 1.00 & 962.00 \\
Cineole & 2.10 & 1024.00 \\
Limonene & 0.20 & 1025.00 \\
Fixed oils and fats & 5.20 & 1051.00 \\
Ketones & 0.10 & 1082.00 \\
Terpene camphor & 0.60 & 1023.00 \\
Tanins & 1.30 & 1164.00 \\
Proteins & 0.30 & 1176.00 \\
Methyl ether & 1.30 & 1215.00 \\
g-Terpinene & 1.00 & 1226.00 \\
Borneol acetate & 0.30 & 1270.00 \\
Amino acids & 38.10 & 1267.00 \\
Carvacrol & 2.30 & 1278.00 \\
Phenolic compounds & 0.20 & 1329.00 \\
Gums and mucilage & 0.10 & 1356.00 \\
Copaene & 0.20 & 1379.00 \\
Carvcrol & 0.10 & 1386.00 \\
Caryophyllene & 3.10 & 1421.00 \\
Saponin & 0.10 & 1509.00 \\
Humulene & 0.10 & 1455.00 \\
Muurolene & 0.30 & 1474.00 \\
Coumarins & 0.10 & 1488.00 \\
Cuparene & 0.10 & 1498.00 \\
p-Cymene & 0.60 & 1507.00 \\
Calamenene B & 0.20 & 1517.00 \\
Caryophyllene oxide & 0.30 & 1534.00 \\
Cadinene & 0.10 & 1678.00 \\
Monoterpene alcohols & 0.50 & 1659.00 \\
Sesquiterpene alcohols & 0.10 & \\
Aldehydes & 0.10 & \\
Ethers & 0.10 & \\
\hline & & \\
& &
\end{tabular}

\section{Test for antimicrobial susceptibility}

The clinical specimens were collected from different sources from the hospital and compared with that of standard strains of the reciprocals to determine the antimicrobial susceptibility towards the Parmotrema perlatum essential oil 10,18-19. The clinical bacterial specimens collected were Staphylococcus species, Streptococcus species, Escherichia species, Pseudomonas species and the fungal yeast Candida species due to its clinical importance. A collection of standard antibiotics was used to compare the antimicrobial activity with that of the Parmotrema perlatum essential oil. The methodology employed was Kirby-Bauer disc diffusion method to determine the susceptibility of each organism by means of zone formations which determines sensitivity of the organism ${ }^{14}$. The minimum dilution required for the Parmotrema perlatum essential oil was determined by using the technique of Minimum Inhibitory-Bactericidal concentration methods using different sets for each specimen. The observation of the results were interpreted and recorded. The results showed a significant values of antimicrobial compounds towards the collected clinical specimens ${ }^{9,20}$. The results achieved were exemplary as described (Tables 2-5).

Table 2: Antimicrobial susceptibility of Staphylococcus isolates

\begin{tabular}{|c|c|c|c|c|c|c|c|c|c|c|c|c|c|c|c|c|}
\hline \multirow[b]{2}{*}{ Specimen } & \multirow[b]{2}{*}{$\mathrm{MIC}$ of oil $\mathrm{dl} / \mathrm{ml}$} & \multirow[b]{2}{*}{ FOX } & \multirow[b]{2}{*}{$E$} & \multirow[b]{2}{*}{$C C$} & \multirow[b]{2}{*}{$F / M$} & \multicolumn{5}{|c|}{ Antimicrobial Susceptibility } & \multirow[b]{2}{*}{$S X T$} & \multirow[b]{2}{*}{$F A$} & \multirow[b]{2}{*}{$L Z D$} & \multirow[b]{2}{*}{$R$} & \multirow[b]{2}{*}{ I } & \multirow[b]{2}{*}{$S$} \\
\hline & & & & & & $V A$ & TEC & $T E$ & $C$ & CIP & & & & & & \\
\hline Nasal specimen & 0.5 & - & - & - & + & + & + & + & * & - & + & + & 5 & 1 & 6 & \\
\hline Otitis specimen & 0.75 & - & - & - & - & + & + & - & + & - & - & - & + & 8 & 0 & 4 \\
\hline Skin & 0.75 & + & + & + & - & + & + & - & + & + & + & - & + & 3 & 0 & 9 \\
\hline Wound specimen & 0.5 & - & - & - & - & + & + & - & + & * & - & - & - & 7 & 1 & 4 \\
\hline Abdominal Cavity Exudate & 0.25 & - & - & - & - & + & + & - & + & - & + & + & + & 6 & 0 & 6 \\
\hline Ulceration & 0.75 & - & + & - & - & + & + & + & + & - & * & + & + & 4 & 1 & 7 \\
\hline Groin & 0.75 & + & + & + & + & + & + & + & + & + & - & + & + & 1 & 0 & 11 \\
\hline Abscess & 0.25 & - & - & - & + & + & + & + & + & - & - & + & + & 7 & 0 & 5 \\
\hline Urine specimen & 0.75 & * & - & + & + & + & + & + & + & - & + & + & - & 4 & 1 & 7 \\
\hline Drain & 0.5 & + & + & + & 一 & + & + & + & + & + & + & + & + & 1 & - & 11 \\
\hline
\end{tabular}

Table 3: Antimicrobial susceptibility of Streptococcus isolates

\begin{tabular}{|c|c|c|c|c|c|c|c|c|c|c|c|c|c|c|c|c|c|c|c|}
\hline \multirow[b]{2}{*}{ Specimen } & \multirow[b]{2}{*}{ MIC of oil $\mathrm{dl} / \mathrm{ml}$} & \multirow[b]{2}{*}{$A M$} & \multirow[b]{2}{*}{$C$} & \multirow[b]{2}{*}{$C I P$} & \multirow[b]{2}{*}{$E$} & \multirow[b]{2}{*}{ FOS } & \multicolumn{6}{|c|}{ Antimicrobial Susceptibility } & \multirow[b]{2}{*}{$S Y N$} & \multirow[b]{2}{*}{ TE } & \multirow[b]{2}{*}{ TEC } & \multirow[b]{2}{*}{$V A$} & \multirow[b]{2}{*}{$R$} & \multirow[b]{2}{*}{ l } & \multirow[b]{2}{*}{$S$} \\
\hline & & & & & & & $F / M$ & $G M$ & $I P M$ & $L N Z$ & $P$ & $S$ & & & & & & & \\
\hline Urine specimen & 0.75 & + & + & + & + & + & + & + & + & * & - & + & - & - & - & - & 5 & 1 & 9 \\
\hline Wound specimen & 0.5 & + & + & - & + & + & + & - & + & - & - & - & - & - & - & - & 9 & 0 & 6 \\
\hline Ulceration & 0.5 & + & + & - & + & + & + & - & + & + & + & - & - & + & + & + & 4 & 0 & 11 \\
\hline Bile & 0.5 & + & + & - & + & + & + & - & + & * & - & - & - & _ & - & - & 8 & 1 & 6 \\
\hline Bedsore Swab & 1.5 & + & + & - & + & + & + & - & + & - & + & + & - & - & - & - & 7 & 0 & 8 \\
\hline Pharynx specimen & 0.5 & + & + & + & + & + & + & + & + & - & * & + & - & - & + & - & 4 & 1 & 10 \\
\hline Health care worker & 0.5 & + & + & + & + & + & + & + & + & + & - & + & - & + & + & + & 2 & 0 & 13 \\
\hline Drain & 0.25 & + & + & + & + & + & + & + & + & - & - & + & - & - & - & - & 5 & 0 & 9 \\
\hline Shelf & 0.25 & + & + & + & + & + & + & + & + & - & + & + & - & * & - & + & 3 & 1 & 11 \\
\hline Disinfection dispenser & 0.25 & + & + & + & + & + & + & + & + & + & + & + & - & + & + & + & 1 & 0 & 14 \\
\hline Blood sample & 0.25 & + & + & - & + & + & + & - & + & - & + & + & - & + & + & + & 4 & 0 & 11 \\
\hline Hospital bed & 0.25 & + & + & + & + & + & + & + & + & - & * & + & - & + & + & + & 2 & 1 & 12 \\
\hline
\end{tabular}


Table 4: Antimicrobial susceptibility of Escherichia isolates

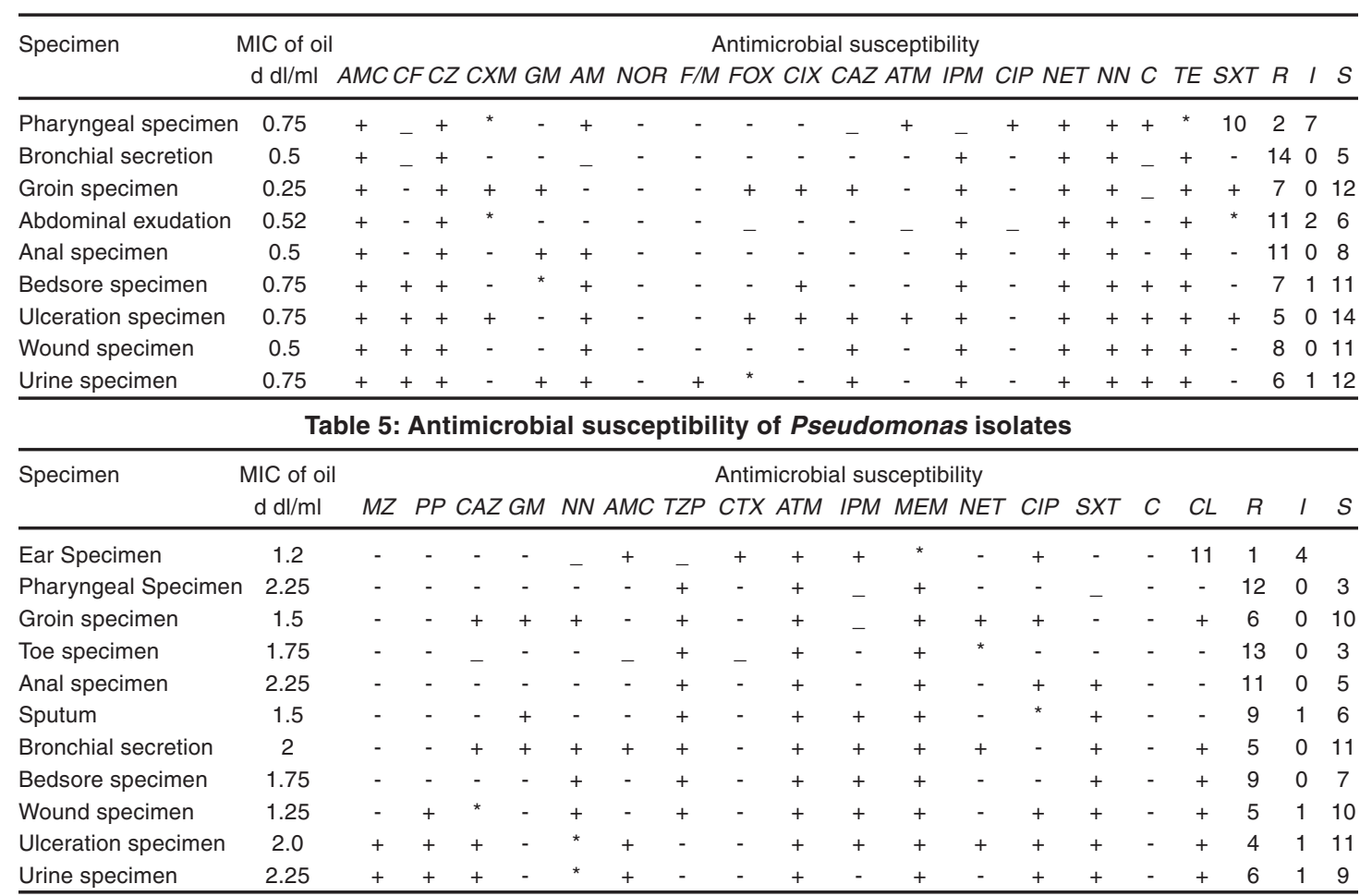

\section{Abbreviations used in Tables 2-5}

Antibiotic Symbols: Cefoxin-FOX; Erythromycin-E; Clindamycin-CC; Nitrofurantoin- F/M; Vancomycin-VA; Teicoplanin-TEC; Tetracycline-TE; Chloramphenicol-C; Ciprofloxacin-CIP; Trimethoprim/ Sulfamethoxazole-SXT; Fisidic acid-FA; LmezolidLZD; Ampicillin-AM;, Fosfomycin-FOS; GentamycinGM; Imipenem-IPM;, linezolid- LZD; Penicillin-P; Streptomycin-S; Synercid-SYN; Amoxicillin/ clavulanic acid-AMC; Cefalotin-CF; Cefazolin-CZ; Cefuroxie-CXM; Norfloxacin-NOR; Cefotaxime-CTX; Ceftazidime-CAZ; Aztreonam-ATM; Netilmicin-NET; Tobramycin-NN; Mezlocillin-MZ; Piperacillin-PIP; Piperacillin/tazobactam-TZP; Meropenem-MEM.;

Resistant- (-) ; Intermediate-(*) ; Sensitive-(+) .

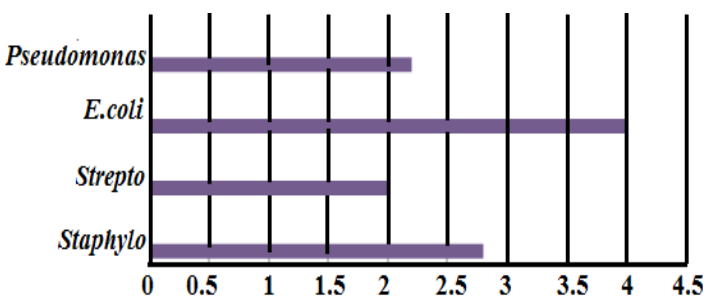

Fig. 1. Comparative chart-antimicrobial minimum inhibitory concentrations-clinically isolated specimens
The Parmotrema perlatum essential oil constitutes of phenolic compounds along with other antimicrobial agents listed (Table 1) analysed from the GC-FID-MS by using a Trace GC Ultra apparatus MS DSQ II detectors and FID-MS splitter under the operating conditions of apolar capillary column to determine the chemical composition which shown as a potential antimicrobial agent due to its chemical properties. The phenolic compounds are excellent antimicrobial substances which were prepared chemically to disinfect bolus of microbial load $^{2-3}$. The phenolic content of the Parmotrema perlatum essential oil may serve as one of the major factor to eliminate the infections as an alternate to the hazardous chemicals. The Parmotrema perlatum essential oil has the potency to eliminate the infection with no serious side effects. The Parmotrema perlatum is a lichen found in the southern parts of India which was used in ancient traditional therapies to treat the infection. This study was an attempt to resurrect the natural traditional methods to treat infections with the nature blessed products rather than seeking the hazardous chemical components produced by the pharmaceutical companies by destroying the eco-system as well as the human immune system ${ }^{5}$. The Parmotrema 
perlatum essential oil is eco-friendly as well as also boosts our immune system to combat the potentially dangerous drug resistant clinical pathogens. In our study, the clinical specimens were collected from different sources from the hospital and compared with that of standard strains of the reciprocals to determine the antimicrobial susceptibility towards the Parmotrema perlatum essential oil. The clinical bacterial specimens collected were Staphylococcus species, Streptococcus species, Escherichia species, Pseudomonas species and the fungal yeast Candida species due to its clinical importance. A collection of standard antibiotics was used to compare the antimicrobial activity with that of the Parmotrema perlatum essential oil. The methodology employed was Kirby-Bauer disc diffusion method to determine the susceptibility of each organism by means of zone formations which determines sensitivity of the organism. The minimum dilution required for the Parmotrema perlatum essential oil was determined by using the technique of Minimum Inhibitory-Bactericidal concentration methods using different sets for each specimen. The observation of the results were interpreted and recorded. The results shown a significant values of antimicrobial compounds towards the collected clinical specimens. The results achieved were exemplary and were proved that even the clinical specimens which were resistant to the antibiotics were also sensitive towards the Parmotrema perlatum essential oil and the MIC values required to inhibit the growth of the clinical infectious specimens was much lesser compared to that of standard antibiotics values. The interpretation of results was done by the comparative values of standard antibiotics with that of Parmotrema perlatum essential oil. The interpretation shows that the antimicrobial activity of the Parmotrema perlatum essential oil is exemplary with that of standard antibiotics (Fig. 1). The clinical specimen of Pseudomonas species which was least susceptible among the bacteria to the standard antibiotics shown susceptibility towards the Parmotrema perlatum essential oil. The clinical specimen of Escherichia species shown excellent susceptibility among all the bacterial clinical specimens. The clinical specimens of the Staphylococcus species and Streptococcus species shown promising values with Parmotrema perlatum essential oil when compared to the standard antibiotics. The clinical specimen of the fungal yeast Candida species was also attempted to check its susceptibility towards Parmotrema perlatum essential oil which shown satisfactory effects and no antifungal drug was used in the study for the comparison. The satisfactory results of the antifungal activity of the Parmotrema perlatum essential oil has open a step forward to study more about the antifungal properties of such essential oils which can help to combat many other fungal infections especially in the prophylaxis of Candidiasis in the diabetes and also in the prophylaxis of vaginitis infections caused by this yeast ${ }^{10,11}$. Elaborate study about the antifungal activity of Parmotrema perlatum essential oil yet to be studied but the preliminary investigations has proved promising results. This study about the Parmotrema perlatum essential oil was an attempt to resurrect and awaken the world about the potential antimicrobial properties present in this types of essential oils as an alternative to the chemical compounds in the antibiotic which are toxic to the living cells to combat the dangerous infection. The major advantage of administering Parmotrema perlatum essential oil is that it will not cause the recurrent infections with no side effects.

\section{CONCLUSION}

The study on Parmotrema perlatum essential oils is an attempt to revoke and resurrect the ancient forgotten technologies to treat the potentially hazardous infections from the microbes by the administration of abundant natural antimicrobial components derives from the gifted nature with no side effects. The WHO has warned that the time with the antibiotics is running out due to our misuse of them which has given rise to the multi-drug resistant organisms and the essential oils such as Parmotrema perlatum essential oil can be an excellent alternative resource.

\section{ACKNOWLEDGEMENT}

We would like to Acknowledge Ibn Sina National College, Jeddah (Kingdom of Saudi Arabia) Administration for their constant support and encouragement due to which our project was possible.

\section{Conflict of interests}

The authors declare no conflict of interest. 


\section{REFERENCES}

1. Beena J., Joji R. Evaluation of antibacterial activity of the leaf and flower essential oils of Gliricidia sepium from south India. Int J Appl Pharm., 2010, 2, 20-22.

2. Pandey B., Ghimire P, Agrawal VP. Organized by Kathmandu University and the Aquatic Ecosystem Health and Management Society, Canada. International Conference on the Great Himalayas: climate, health, ecology, management and conservation, Kathmandu., 2004.

3. Alanis AJ. Resistance to antibiotics: Are we in the post-antibiotic era? Arch Med Res., 2005, 36, 697-705.

4. Bekhechi C., Bekkara FA, Abdelouahid DE, Tomi F, Casanova J. Composition and Antibacterial Activity of the Essential Oil of Thymus fontanesii Boiss. et Reut. from Algeria. J Essent Oil Res., 2007, 19, 594-596.

5. Dal Sasso M. Thymol: Inhibitory Activity on Escherichia coli and Staphylococcus aureus Adhesion to Human Vaginal Cell. J Essent Oil Res., 2006, 18, 455-461.

6. Lis-Balchin M., Deans S, Hart S. Bioactivity of Geranium Oils from Different Commercial Sources. J Essent Oil Res., 1996, 8, 281-290.

7. Walsh TR., Toleman MA, Poirel L, Nordmann P. Metallo- $\beta$-Lactamases: the Quiet before the Storm? Clin Microbiol Rev., 2005, 18, 306-325.

8. Wimmerstedt A., Kahlmeler G. Associated antimicrobial resistance in Escherichia coli, Pseudomonas aeruginosa, Staphylococcus aureus, Streptococcus pneumonia and Streptococcus pyogenes. Clin Microbiol Infect., 2008, 14, 315-321.

9. Berdy J. Bioactive microbial metabolites. $J$ Antibiot., 2005, 58, 1-26.

10. Manosroi J., Dhumtanom P, Manosroi A. Antiproliferative activity of essential oil extracted from Thai medicinal plants on KB and P388 cell lines. Cancer Lett., 2006, 235, 114-120.

11. Atta HM. An Antifungal Agent Produced by Streptomyces olivaceiscleroticus, AZ-SH514.
World Appl Sci J., 2009, 6, 1495-1505.

12. Teixeira AP., Batista O, Simões MF, Nascimento J, Duarte A, de la Torre MC. Abietane diterpenoids from Plectranthus grandidentatus. Phytochemistry., 1997, 44, 325-327.

13. Adams RP. Identification of Essential oil Components by Gas Chromatography/Mass Spectroscopy, $4^{\text {th }}$ edition. Allured Publishing Corporation, Carol Stream. IL., 2007.

14. Gouse BS., Muazzam SM, Gokul SS, Ranjith MS. Isolation and characterization of actinomycetes from soil of ad-dawadmi, saudi arabia and screening their antibacterial activities. Int $J$ of Pharm and Pharmaceutical Sc., 2017, 9(10), 267-279.

15. Sader HS., RN Jones. Antimicrobial susceptibility of Gram-positive bacteria isolated from US medical centers: results of the Daptomycin Surveillance Program (2007-2008) Diagn Microbiol Infect Dis., 2009, 65, 158-162.

16. [CLSI] Clinical and Laboratory Standard Institute. 2009. Performance Standards for Antimicrobial Susceptibility Testing: Nineteenth Informational Supplement. CLSI Document M100-S19. Clinical and Laboratory Standard Institute, Wayne, PA., 2009.

17. Sujatha P., Swethalatha P. Isolation and screening of novel Streptomyces from sediments of bay of Bengal near Srikakulam coast. Int J Curr Pharm Res., 2016, 9, 40-44.

18. Butt T., Usman M, Ahmad RN, Saif I. Emergence of Metallo-beta-lactamase producing $P$. aeruginosa in Pakistan. $J$ Pak Med Assoc., 2005, 55, 302-304.

19. Howe RA., Brown NM, Spencer RC. The new threats of Gram positive pathogens: re-emergence of things past. J Clin Pathol., 1996, 49, 444-449.

20. Shin S., Kim J. In vitro inhibitory activities of essential oils from two KoreanThymus species against antibiotic-resistant pathogens. Arch Pharm Res., 2005, 28, 897-901. 